\title{
Research progress on the preparation of concrete with large amount of iron tailings
}

\author{
Xiaowei $\mathrm{Gu}^{1}$, Haofeng $\mathrm{Chi}^{2}$, Jianping $\mathrm{Liu}^{2 *}$, Peng $\mathrm{Liu}^{2}$, Ziyang $\mathrm{Hu}^{2}$, Huiwen Zhang ${ }^{2}$ \\ ${ }^{1}$ Northeastern University, Shenyang, Liaoning, China \\ ${ }^{2}$ Department of Architecture and Civil Engineering, Shenyang University of Technology, Shenyang, Liaoning, China
}

\begin{abstract}
Recently, the use of sustainable materials has gained increasing attention and recognition, especially in the construction industry. As the main component of concrete, ordinary Portland cement (OPC) is undoubtedly one of the most commonly used building materials in the world. However, the manufacture of OPC is accompanied by environmental and ecological problems such as the release of carbon dioxide. According to estimates, about $5 \%-8 \%$ of the world think that carbon dioxide emissions come from the OPC industry, so it is urgent to use fly ash, tailings, slag and other industrial solid waste to produce cement instead of ordinary Portland cement.This article summarizes the achievements of the predecessors and outlines the influence of different iron tailings and iron tailings content on the mechanical properties and durability of concrete.
\end{abstract}

\section{Introduction}

Iron tailings are wastes eliminated during beneficiation and are also an important part of industrial solid waste. It is a hazard to the environment and people's lives and property safety. However, there are not too many ways to use iron tailings, only a 1 arge amount of accumulation. Not only occupying space seriously, but also endangering land resources. According to 《Report on China's Mineral Resources Conservation and Comprehensive Utilization》 [1], as of the end of 2017, the domestic tailings stockpile was 19.5 billion tons. We should find ways to use these discarded iron tailings to make concrete, which can not only solve a series of problems caused by the accumulation of iron tailings, but also meet the needs of building structures for concrete. The advantages of this material are high strength, strong acid resistance, large consumption of hazardous solid waste and greatly reduce greenhouse gas emissions. The most important thing is to save capital and also consume a lot of iron tailings. The article summarizes the method of preparing concrete with a large amount of iron tailings and the influence of iron tailings on the strength and durability of concrete.

\section{Current research status of iron tailings mixing concrete}

The storage of tailings requires a large amount of land, and the heavy metal ions and chemicals contained in the tailings will flow into nearby rivers or infiltrate the ground with the tailings water,seriously polluting rivers and underground water sources; the fine tailings on the surface after natural drying will be formed in strong wind Dust and sandstorms blow to the surrounding areas and cause serious impacts on the ecological environment; The greater the height of the dam, the higher the risk, especially for large tailings ponds with a dam height of more than $100 \mathrm{~m}$. Once a dam collapse accident occurs, the consequences will be disastrous. On September 8,2008, the collapse of the Xiangfen tailings pond in Shanxi gave people another knock. Alarm bell rang ${ }^{[2-4]}$.

Scholars have done a lot of research on iron tailings concrete. In 2018, Wang ${ }^{[5]}$ Using lead-zinc tailings as a substitute for cement, super-performance concrete is obtained, and the leaching toxicity is lower than the national standard; In 2016, Guo ${ }^{[6]}$ Calcining and grinding are used to stimulate the pozzolanic activity of pyrite flotation tailings, and adding it to concrete can make the concrete have good performance. Mainly focused on: changing the content of iron tailings concrete admixture, the effect of different iron tailings on concrete performance, improving the basic mechanical properties of concrete, and the influence of activated iron tailings powder on concrete performance.

\subsection{Influence of iron tailings content on concrete performance}

In $2020, \quad$ Xiao Tong ${ }^{[7]}$ Through 12 groups of 216 $100 \mathrm{~mm} \times 100 \mathrm{~mm} \times 100 \mathrm{~mm}$ non-standard concrete test blocks, the performance of recycled concrete with different content of iron tailings and recycled aggregates was studied. The results show that the compressive strength of concrete tends to decrease first and then increase when the content of coarse aggregate is less than $30 \%$; When the coarse aggregate content reaches $30 \%$, the compressive strength reaches the maximum value of $38.34 \mathrm{MPa}$. When 
the amount of iron tailings mixed reaches $30 \%$, the degree of hydration reaches the maximum, and the interior of the concrete is denser.During the 28-day period of concrete curing, the hydration degree of iron tailings continues to

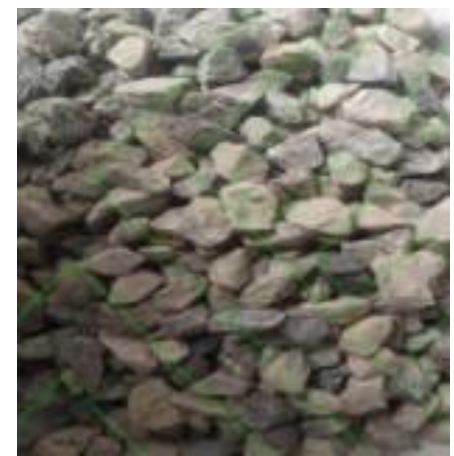

Figure 1 Iron tailings

In 2019, Lei Yao ${ }^{[8]}$ used the method of preparing ordinary concrete to mix concrete with three strength levels of $\mathrm{C} 30, \mathrm{C} 40$, and C50. After grading optimization of natural sand, artificial sand and iron tailing sand, different The influence of the iron tailings sand on the performance of different grades of concrete. The results show that: The workability of iron tailing sand concrete is obviously lower than

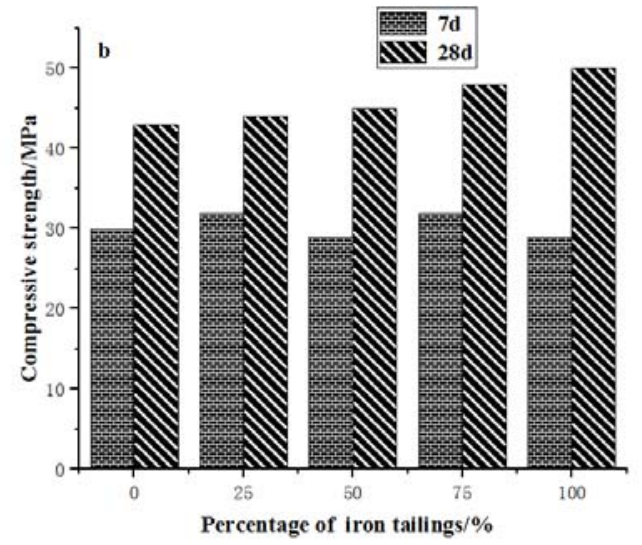

increase as the age increases. When the output of coarse aggregate and iron tailings both reach $30 \%$, the coarse aggregate and cement slurry in the concrete are most closely combined.

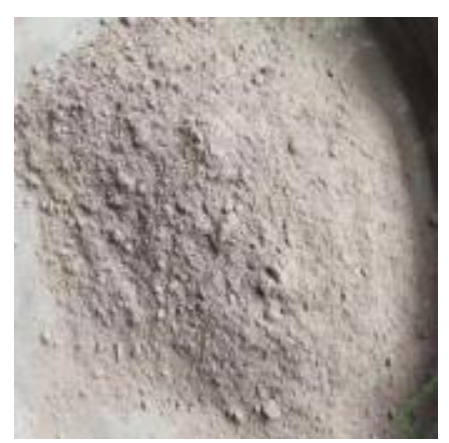

Figure 2 Recycled coarse aggregate

that of ordinary concrete. As the content increases, the concrete slump becomes smaller; For C30 and C40 concrete, the more iron tailing sand content, the higher the concrete strength, which is higher than ordinary concrete. For C50 strength iron tailings concrete, the strength is lower than ordinary concrete.

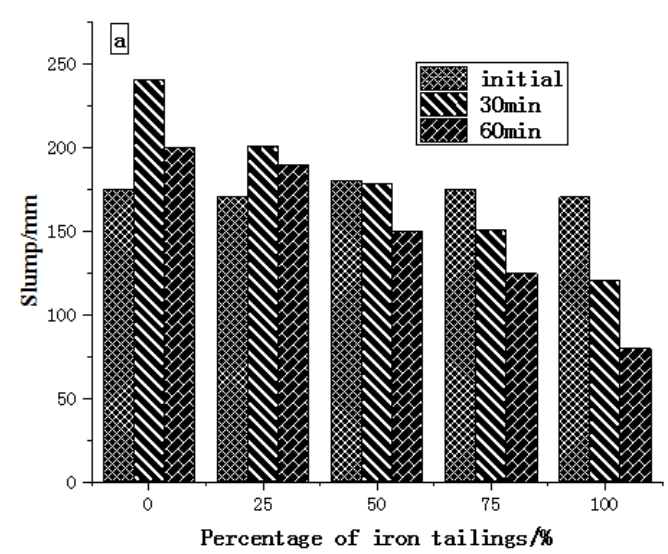

Figure 3 The effect of iron tailings on the compressive strength and slump of concrete ${ }^{[8]}$

In 2016, Yu Zhuo Zhang ${ }^{[9]}$ prepared concrete by mixing different proportions of iron tailings sand with natural sand, then through the adjustment of the gradation of different proportions of admixtures, the concrete consistency and strength were tested. research shows: As the iron tailing sand increases to a certain proportion, the particle gradation is improved. When the iron tailing sand content reaches $50 \%$, the concrete fluidity meets the construction requirements; when the curing age reaches $28 \mathrm{~d}$, the iron tailing sand concrete compresses The strength is significantly higher than that of ordinary concrete. As the content of iron tailings increases, the compressive strength gradually increases, but the splitting strength decreases.

In 2014, Xiuzhi Zhang ${ }^{[10]}$ studied the working performance, mechanical properties, durability and drying shrinkage properties of concrete prepared from iron tailings sand and machine-made sand in different proportions, the results showed: The compressive strength of iron tailings concrete of the same age is higher than that of ordinary concrete. When the mixing ratio of iron tailings sand and machine-made sand reaches $6: 4$, the working performance, compressive strength, and durability of iron tailings concrete are equal. Close to ordinary concrete.

In 2010, Dezhong Li ${ }^{[11]}$ used Shougang's Miyun iron tailings to classify, and mixed-0.08mm grain iron tailings with cement clinker and desulfurized gypsum into a threestage cementing agent. Then the cementing agent, The water reducing agent is mixed with $+0.08 \mathrm{~mm}$ iron tailings to make concrete. The influence of aggregate size, mixing time and water reducing agent dosage on the compressive strength of concrete was analyzed by orthogonal experiment. The results show that the main factor affecting the compressive strength of concrete is the mixing time; the $28 \mathrm{~d}$ compressive strength of iron tailings concrete 
prepared by this method can reach $97.63 \mathrm{MPa}$, and the iron tailings content is $70 \%$.

\subsection{The influence of different iron tailings on concrete performance}

In 2019, Xiao ran Ping ${ }^{[12]}$ prepared concrete from vanadium-titanium-iron tailings and analyzed it by laser particle size analysis, XRD, XRF, SEM and other methods. The results showed: The concrete prepared by this method has better performance. When the tailings powder content reaches $16 \%$, the $3 \mathrm{~d}$ and $28 \mathrm{~d}$ compressive strengths of $\mathrm{C} 30$ tailings concrete reach $13.4 \mathrm{MPa}$ and $40.3 \mathrm{MPa}$. With the increase of tailings content, the freeze-thaw resistance ability is greatly improved, and the number of freeze-thaw cycles reaches 125 times, which is nearly 100 times more than that of ordinary concrete.

In 2019, Kui Mao ${ }^{[13]}$ used eight types of iron tailings from Anshan in Liaoning, Daye of Huangshi in Hubei,

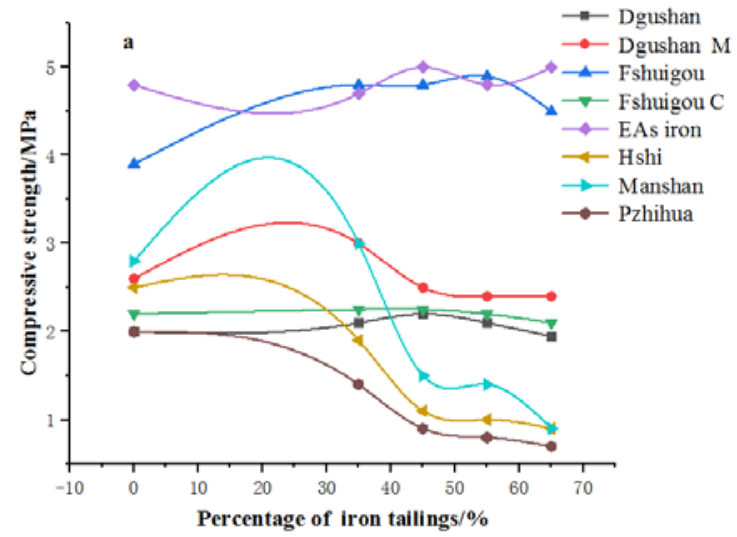

Ma'anshan in Anhui, and Panzhihua in Sichuan to prepare iron tailings aerated concrete. Through XRD, FTYR, SEM and other methods, the effect of different iron tailings and different iron tailings content on the performance of aerated concrete is analyzed. The results show that: When the maximum content of Anshan iron tailings reaches 55\%, the compressive strength of iron tailings concrete can reach A05 level and the dry density can reach B07 level.And with the increase of iron tailings content, increase first and then decrease. Under steam pressure curing, the calcium material in the iron tailings aerated concrete is hydrated into $\mathrm{CaOH}$ and reacted with $\mathrm{SiO} 2$ and $\mathrm{CaO}$ in the tailings to form torbe mullite. The ettringite in the sample disappears, and the torbe mullite and The aggregates are adsorbed together to obtain a dense structure, which is a great improvement in the strength of concrete. The figure below shows the effect of different proportions of iron tailings on the performance of concrete prepared from iron tailings in different regions.

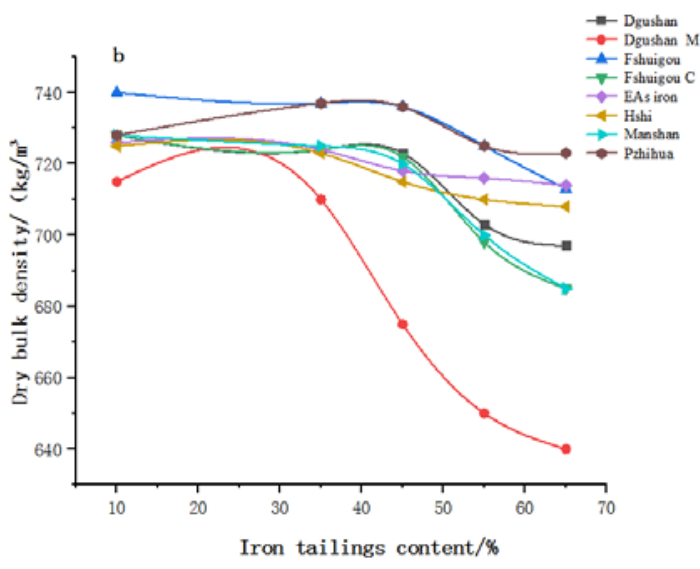

Figure 4 The influence of different iron tailing sand content on the performance of concrete prepared by iron tailings in different regions $^{[13]}$

\subsection{The influence of iron tailings on the anti-car- bonation performance and durability of concrete}

In 2020, Sun Qiurong ${ }^{[14]}$ studied the carbonization resistance and compressive strength of iron tailings concrete under carbonization conditions. Then, the water-binder ratio, iron tailings content and the amount of cementitious materials were analyzed through orthogonal experiments. The results show that the most important factors affecting the anti-carbonization ability of iron tailings concrete are the water-binder ratio and iron tailings content, and as the iron tailings content increases, the concrete's anti-carbonation ability becomes weaker. When the waterbinder ratio reaches 0.4 , The concrete has the strongest carbonization resistance.

In 2019 , Ketang ${ }^{[15]}$ studied the influence of iron tailings concrete on the workability, mechanical properties and durability of iron tailings concrete by adjusting different mix ratios. After analyzing the workability, compressive strength, flexural tensile strength and mechanical properties of iron tailings concrete, better iron tailings concrete is selected for frost resistance and salt corrosion resistance analysis. The results show that: When the iron tailing content is between $25 \%$ and $50 \%$, the workability and mechanical properties of concrete are greatly improved. After the freeze-thaw cycle and $\mathrm{Na}_{2} \mathrm{SO} 4$ erosion cycle test, the results show: The quality change range of iron tailings concrete specimens is obviously smaller than that of ordinary concrete specimens; when the iron tailings content reaches $75 \%$, the quality change range is the smallest. Obviously, the addition of iron tailings can improve the compactness of concrete, reduce moisture, and Prevent the intrusion of sulfate and reduce the damage of concrete.

In 2016, Wei Zhang ${ }^{[16]}$ studied the effect on concrete slump and compressive strength through experiments on iron tailings powder and iron tailings powder-fly ash-slag powder compound mixing to prepare concrete. The results show As the content of iron tailings increases, the slump of the concrete with single iron tailings increases first and then decreases, and the compressive strength decreases. The optimal content is $15 \%$; The strength, workability and compressive strength of concrete with iron tailings are significantly improved. 
Table 1 The mix ratio and carbonization depth of each group of concrete in the orthogonal test ${ }^{[14]}$

\begin{tabular}{|c|c|c|c|c|c|c|c|c|c|c|}
\hline \multirow{2}{*}{$\begin{array}{l}\text { Num- } \\
\text { bering }\end{array}$} & \multicolumn{6}{|c|}{ Ratio/ $\left(\mathrm{kg} \cdot \mathrm{m}^{-3}\right)$} & \multicolumn{4}{|c|}{ Carbonization depth $/ \mathrm{mm}$} \\
\hline & cement & $\begin{array}{l}\text { River } \\
\text { sand }\end{array}$ & $\begin{array}{l}\text { Iron tail- } \\
\text { ings }\end{array}$ & gravel & water & $\begin{array}{c}\text { Water re- } \\
\text { ducing } \\
\text { agent }\end{array}$ & $3 d$ & $7 d$ & $14 \mathrm{~d}$ & $28 \mathrm{~d}$ \\
\hline 1 & 380 & 110 & 625 & 1102 & 133 & 3.8 & 6.3 & 8.5 & 16.0 & 21.5 \\
\hline 2 & 400 & 217 & 507 & 1086 & 140 & 4.0 & 7.5 & 10.0 & 18.0 & 24.0 \\
\hline 3 & 420 & 321 & 392 & 1070 & 147 & 4.0 & 11.0 & 17.0 & 30.5 & 37.5 \\
\hline 4 & 400 & 107 & 606 & 1074 & 160 & 4.0 & 4.5 & 6.0 & 13.0 & 18.5 \\
\hline 5 & 420 & 211 & 492 & 1059 & 168 & 4.5 & 6.0 & 8.0 & 14.0 & 20.5 \\
\hline 6 & 380 & 327 & 400 & 1090 & 152 & 4.0 & 4.0 & 5.0 & 15.0 & 21.0 \\
\hline 7 & 420 & 104 & 592 & 1045 & 189 & 4.0 & 4.6 & 6.0 & 14.5 & 22.0 \\
\hline 8 & 380 & 215 & 502 & 1082 & 171 & 3.5 & 6.5 & 10.5 & 18.0 & 25.0 \\
\hline 9 & 400 & 318 & 389 & 1063 & 180 & 4.0 & 10.0 & 14.0 & 30.0 & 33.5 \\
\hline
\end{tabular}

\subsection{The influence of activated iron tailings pow- der on concrete performance}

In 2020, Jing Sun ${ }^{[17]}$ conducted a study on the optimization of the mix ratio based on the mechanical properties of concrete, by controlling the water-binder ratio, colloidal aggregate ratio, quartz content, gradation, fly ash grinding time, silica fume and steel fiber content In addition, iron tailings were used to replace quartz and silica fume. After orthogonal experiments, the compressive strength and flexural strength of concrete were obtained. Finally, the design-expert software was used to analyze the mix ratio. The final result shows that the concrete made by using iron tailings instead of silica fume and quartz; among them, the water-binder ratio and gradation are the main factors affecting the compressive strength of concrete, and the factors that have the greatest influence on the flexural strength are the amount of steel fiber and pulverized coal Ash grinding time.

In 2020, Chun Ai Piao ${ }^{[18]}$ studied the impact on the mechanical properties and durability of $\mathrm{C} 30$ and $\mathrm{C} 60$ concrete through single and compound activated iron tailings powderThe results show that when the single mixing ratio is below $40 \%$, with the continuous increase of iron tailings powder, the single mixing iron tailings powder has more advantages in improving the workability of concrete. The ability of composite double-doped iron tailings powder to improve the fluidity of concrete is obviously higher than that of single-doped iron tailings powder, and the maximum mixing amount can reach $60 \%$. The compressive strength of composite double-mixed concrete during the $3 \mathrm{~d}$ curing age is significantly lower than that of singlemixed concrete, but as the curing age increases, the later compressive strength is higher than that of single-mixed activated iron tailings powder concrete.Concrete mixed with activated iron tailings can improve the performance of concrete in both strength grades higher than that of iron tailings powdered concrete, but slightly lower than iron tailings powdered concrete in terms of anti-carbonization ability.

In 2019, Mengchanwang ${ }^{[19]}$ prepared geopolymers by adding a small amount of metakaolin from low-silicon iron tailings. The effects of different activators, activation methods and activation process parameters on the oligomers prepared from low-silicon iron tailings were studied, and the geopolymers were microscopically analyzed.The results showed that when the ratio of low-silica tailings to metakaolin reached $1: 1$, the $3 \mathrm{~d}, 7 \mathrm{~d}$, and $28 \mathrm{~d}$ maximum compressive strengths of the prepared oligomers reached 55.6MPa, 68.0MPa, and 72.3MPa, respectively.Activated low-silicon iron tailings can significantly increase the strength of the geopolymer. Through experiments, it is found that the use of $\mathrm{NaOH}$ lye is the best. The $7 \mathrm{~d}$ maximum compressive strength of the prepared geopolymer is $82 \mathrm{MPa}$. The properties of geopolymers can be further improved through proper curing condition optimization and activation activation, and the prepared geopolymers have high early strength and good durability.

\section{Engineering application}

In recent years, the application of tailings concrete in actual construction projects has been launched ${ }^{[20]}$. Shougang Construction Group has so far produced $350,000 \mathrm{~m}^{3}$ iron tailings concrete, consuming $240,000 \mathrm{~m}^{3}$ iron tailings. The field includes important engineering projects such as cover blast furnace foundation, large belt corridor support foundation, and blast furnace approach bridge deck.

In the permanent building of Chengde Shuangfengsi Reservoir Project RCC [21], iron tailings concrete was used for $562,200 \mathrm{~m}^{3}$, of which $380,300 \mathrm{~m}^{3}$ of roller compacted concrete, 44,700 $\mathrm{m}^{3}$ and 137,200 $\mathrm{m}^{3}$ of abnormal and 
normal concrete were used. .

During the bridge construction of the Beijing-Chengdu Expressway (Phase 3) project undertaken by the Fifth Engineering Co.Ltd. of China Communications First Public Bureau ${ }^{[22]}$, iron tailings were used as the coarse aggregate in the concrete preparation, which cleaned up a lot of The reserves of iron tailings and the research and development of advanced technologies have brought great social, economic and ecological benefits.

From June 2008 to January 2009, we carried out engineering application tests in a concrete company under the municipal road and bridge building materials group ${ }^{[23]}$, using 8000t of Beijing Miyun iron tailings, applied to civil construction projects, a total of $20,000 \mathrm{~m}^{3} \mathrm{C} 15$ to $\mathrm{C} 50$ iron tailings concrete.

Since 2008, in municipal and civil construction projects ${ }^{[24}$, mixed sand composed of iron tailing sand or iron tailing sand, machine-made sand, and natural sand has been used to prepare $\mathrm{C} 10 \sim \mathrm{C} 60$ grade concrete. In the application of similar concrete, about 300,000 tons of iron tailing sand is used, which has achieved a good demonstration project application.

Table 2 Summary of existing research on iron tailings concrete

\begin{tabular}{|c|c|c|c|c|c|c|}
\hline Date & Raw materials & scholar & $\begin{array}{l}\text { Source of tail- } \\
\text { ings }\end{array}$ & $\begin{array}{l}\text { Optimal dos- } \\
\text { age }\end{array}$ & Durability & $\begin{array}{c}\text { Maximum compressive } \\
\text { strength }\end{array}$ \\
\hline & Iron tailings & & & & Better than or- & \\
\hline 2020 & $\begin{array}{l}\text { Recycled ag- } \\
\text { gregate }\end{array}$ & XiaoTong $^{[7]}$ & Shangluo & $30 \%$ & $\begin{array}{l}\text { dinary con- } \\
\text { crete }\end{array}$ & $38.34 \mathrm{MPa}$ \\
\hline 2019 & $\begin{array}{l}\text { Iron tailings } \\
\text { Desulfuriza- } \\
\text { tion gypsum }\end{array}$ & $\begin{array}{c}\text { Dezhong } \\
\text { Lee }^{[8]}\end{array}$ & Beijing & $70 \%$ & $\begin{array}{l}\text { Better than or- } \\
\text { dinary con- } \\
\text { crete }\end{array}$ & $97.63 \mathrm{MPa}$ \\
\hline 2016 & $\begin{array}{l}\text { Iron tailings } \\
\text { Natural sand }\end{array}$ & Lei $\mathrm{Yao}^{[9]}$ & Tangshan & $60 \%$ & $\begin{array}{l}\text { Close to river } \\
\text { sand concrete }\end{array}$ & $57.5 \mathrm{MPa}$ \\
\hline 2016 & $\begin{array}{c}\text { Iron tailings } \\
\text { Fly ash }\end{array}$ & Wei Zhang ${ }^{[16]}$ & Anshan & $30 \%$ & $\begin{array}{l}\text { Close to river } \\
\text { sand concrete }\end{array}$ & $56 \mathrm{MPa}$ \\
\hline 2010 & $\begin{array}{c}\text { Iron tailings } \\
\text { Machine-made } \\
\text { sand }\end{array}$ & $\begin{array}{c}\text { Xiuzhi } \\
\text { Zhang }{ }^{[11]}\end{array}$ & Tai'an & $20 \%$ & $\begin{array}{l}\text { Close to river } \\
\text { sand concrete }\end{array}$ & $66 \mathrm{MPa}$ \\
\hline 2019 & $\begin{array}{l}\text { Vanadium il- } \\
\text { menite tailings }\end{array}$ & $\begin{array}{l}\text { Xiao Ran } \\
\operatorname{Lin}^{[12]}\end{array}$ & Chengde & $16 \%$ & $\begin{array}{l}\text { Close to ordi- } \\
\text { nary concrete }\end{array}$ & $40.3 \mathrm{MPa}$ \\
\hline 2019 & Iron tailings & Kui Mao ${ }^{[13]}$ & Eight regions & $55 \%$ & & A05 level \\
\hline 2019 & $\begin{array}{l}\text { Iron tailings } \\
\text { Metakaolin }\end{array}$ & $\begin{array}{l}\text { Mengchan } \\
\text { Wang }^{[19]}\end{array}$ & Daye & $\begin{array}{c}\text { Iron tailings / } \\
\text { metakaolin }= \\
1: 1\end{array}$ & $\begin{array}{l}\text { Good perfor- } \\
\text { mance in some } \\
\text { way }\end{array}$ & $72.3 \mathrm{MPa}$ \\
\hline
\end{tabular}

\section{Conclusion}

As a bulk of industrial solid waste, iron tailings have been stacked in large quantities and have already caused serious impacts on the surrounding environment. Therefore, it has become an inevitable trend to use iron tailings in many ways. The performance improvement has been very obvious. At present, the preparation technology of iron tailings concrete is continuously improving.

(1) Iron tailings concrete is prepared by mixing cement, iron tailings waste rock, iron tailing sand or iron tailing sand and natural sand, admixture and water according to a certain mixing ratio, according to variable curing conditions. The compressive strength, durability, resistance to carbonization and freeze-thaw resistance of ordinary concrete are roughly the same or even better.

(2) The small and medium-sized iron tailings powder of iron tailings can improve the carbonization resistance, freeze-thaw resistance and corrosion resistance of iron tailings concrete, and can also form a dense structure inside the iron tailings concrete, making the concrete more dense . For the durability of iron tailings concrete, the compressive strength and split tensile strength during the standard curing age are also improved compared to ordinary concrete. 


\section{References}

1. Yi LS. (2020) Current Status of Comprehensive Utilization of Tailings Resources in China[J].Mineral Resources Conservation and Utilization,40(03):7984.

2. Xing ZJ. (2015) Research on Comprehensive Utilization and Industrialization Promotion Technology of Iron Tailings in my country[J].Technological Innovation and Application,24:75-76.

3. Xiao LG. (2010)The status quo of comprehensive utilization of iron tailings at home and abroad[J].Journal of Jilin Institute of Civil Engineering and Architecture,27(4):22-26.

4. Zhu ZG. (2013) Study on the preparation of reactive powder concrete from iron tailings[D].Wuhan:Wuhan University of Technology.

5. WANG X. (2018) Development of a novel cleaner construction product:Ultra - high performance concrete incorporating lead-zinc tailings $[\mathrm{J}]$. Journal of Cleaner Production, 196:172-182.

6. GUO Z. (2016) Study on flotation tailings of kaolinite-type pyrite when used as cement admixture and concrete admixture $[\mathrm{J}]$. Procedia Environmental Sciences, 31:644-652.

7. Tong X. (2020)Analysis of mechanical properties and microstructure of iron tailings recycled aggregateconcrete[J/OL]Concrete: 1-

4.http://kns.cnki.net/kcms/detail/21.1259.TU.20200804.1051.022.html.

8. Yao L. (2019) The influence of iron tailing sand content on concrete performance $[\mathrm{J}]$.Concrete and Cement Products(10):97-100.

9. Zhang YZ. (2016)Experimental Research on Iron Tailings Used in Concrete Fine Aggregate[J].Nonmetallic Mine 39(6):57-59+66.

10. Zhang XZ. (2014)Study on the performance of iron tailing sand/machine-made sand to prepare high performance concrete[J].Concrete(03):116-118+123.

11. Li DZ. (2010)Preparation of high-strength concrete material with large amount of iron tailings[J].Metal Mine(02):167-170.

12. Lin XR. (2019) Study on the preparation of readymixed concrete with vanadium-titanium-iron tailings as admixture[D].Hebei University of Engineering.

13. Mao K. (2019) Study on the performance and hydration mechanism of aerated concrete prepared from several typical iron tailings[J].The Chinese Ceramics Bulletin,38(12):3719-3725.

14. Sun QR. (2020)Experimental study on anti-carbonization performance of iron-containing tailings concrete[J].Iron and Steel Vanadium and Titanium, 41(02):82-88.

15. Tang K. (2019)Performance analysis of cement concrete mixed with iron tailings fine aggregate[J].Industrial Construction 49(08):153-157.

16. Zhang W. (2016) Effect of iron tailings powder-fly ash-slag powder composite admixture on concrete properties [J].Bulletin of the Chinese Ceramic Society,35(11):3826-3831.

17. Sun J. (2020)Experimental Research on Optimization of Mixture Ratio of Iron Tailings Reactive Powder Concrete Based on Design-expert[J].Bulletin of the Chinese Ceramic Society,39(03):762-769.

18. Piao CA. (2020)Research on the influence of CMITMIT activated iron tailings powder system on concrete performance[J].Bricks and Tiles,(05):15-20.

19. Wang MC. (2019) Preparation and performance of low-silicon iron tailingsgeopolymer[D]. Wuhan University of Science and Technology.

20. Pu NR. (2017) The status quo and development of iron tailings concrete[J].Building Materials and Decoration,(05):191-192.

21. Wang TQ. ( 2015 ) Application of Iron Tailings Powder in Chengde Shuangfeng Temple RollerCompacted Concrete Dam[J].South-to-North Water Diversion and Water Conservancy Science and Technology,13(01):148-152.

22. Geng ZJ. ( 2010 ) Application of Iron Tailings Crushed Rock in Bridge Concrete[J].Highway and Transportation Science and Technology(Applied Technology Edition),6(10):325-327.

23. Tian JS. (2009)Research on Resource Utilization Technology of Iron Tailings in Cement Concrete in Beijing Area[J].Building Decoration Materials World,(02):33-45.

24. Tian JS. (2010) Study on the preparation and application of iron tailing sand concrete[D]. Beijing: Tsinghua University. 